Article

\title{
"Everyone Is Normal, and Everyone Has a Disability": Narratives of University Students with Visual Impairment
}

\author{
Nitsan Almog ${ }^{1,2}$ \\ ${ }^{1}$ Department of Education and Societal Studies, Ono Academic College, 5545173 Kiryat Ono, Israel; \\ E-Mail: nitsanalmog@gmail.com \\ 2 Louis and Gabi Weisfeld School of Social Work, Bar-Ilan University, 5290002 Ramat Gan, Israel
}

Submitted: 22 July 2018 | Accepted: 24 September 2018 | Published: 6 December 2018

\begin{abstract}
University students with visual impairment in Israel and worldwide face multiple academic and social barriers and must develop techniques, strategies and skills to adjust to the university environment. The current article is based on a longitudinal qualitative study aimed at incorporating students' voices and offers some insight into the ways students experience their academic journeys. The research method combined grounded theory with the emancipatory disability research paradigm, which draws explicitly from people with disabilities' collective experience and thus directly challenges this group's widespread social oppression. This combination allowed the researcher to focus on students' initial experiences as subjectively perceived. Sixteen students all defined as legally blind, from four universities in Israel, were interviewed over a 2-year period of their studies. The findings present two complementary narratives the interviewees used while configuring their identities. The article will focus on findings that suggest that during their academic journeys, students needed to manage a process of integrating their identity both as disabled and as students, choosing when and where to perform each identity and determining what the implications of each choice were along with each one's related costs and benefits. The study's implications and recommendations can help professionals and support services improve inclusion and equality in higher education.
\end{abstract}

\section{Keywords}

disability studies; higher education; identity; students; visual impairment

\section{Issue}

This article is part of the issue "Students with Disabilities in Higher Education", edited by Geert Van Hove (Ghent University, Belgium/VU Amsterdam, The Netherlands), Minne Bakker (VU Amsterdam, The Netherlands) and Alice Schippers (Disability Studies in the Netherlands/VU Amsterdam, The Netherlands).

(C) 2018 by the author; licensee Cogitatio (Lisbon, Portugal). This article is licensed under a Creative Commons Attribution 4.0 International License (CC BY).

\section{Introduction: Research Background}

In the last three decades, the number of university students with disabilities in Israel and elsewhere has increased steadily (Bruder \& Mogro-Wilson, 2010; Heiman, Almog, \& Godder, 2006; Wisbey \& Kalivoda, 2016). This increase resulted from policy changes that broaden access to higher education and from legislative processes ensuring the rights of people with disabilities (Riddell, Tinklin, \& Wilson, 2005; Vickerman \& Blundell, 2010), including ratification of the Convention on the Rights of People with Disabilities (CRPD), which mandates the right to higher education (Kanter, 2015) and from the implementation of Israel Equal Rights for People with Disabilities Law of 1998. Similar to the Americans with Disabilities Act (ADA), this Israeli law demands full inclusion for individuals with disabilities, declaring the right of people with disabilities to be equal members of society, treated with respect and support (Vilchinsky \& Findler, 2004). Although the law's regulations regarding the accessibility of higher education institutions were enacted in 2016, they were scheduled to take full effect by the end of 2018. In the meantime, Israeli higher education institutions continue to write disability provisions into their policies and are progressing in terms of accommodations and support services for students with disabilities. 
People with disabilities have lower employment rates than the rest of the population does, no matter their qualification level. In Israel, only $51 \%$ of workingage persons with disabilities are employed compared with an employment rate of $79 \%$ for the rest of the population (Barlev, Admon-Rick, Keren-Abraham, \& Haber, 2017). Nonetheless, the employment rate for people with disabilities with academic degrees was higher (74.3\%; Berman \& Naon, 2004; Pinto \& Fass, 2014) but remains lower than that of nondisabled graduates (88.2\%; Israeli Ministry of Economy, 2013). The situation of the legally blind population in Israel is even worse, as only $33 \%$ of those of working age (19-64) are employed (Monikendam-Givon, 2017). However, the employment rate among legally blind university graduates is extremely high at $68 \%$ but still $20 \%$ lower than that of the nondisabled university graduate population (Berman \& Naon, 2004; Naon et al., 2012).

Despite the increase in the number of students with disabilities and the growing understanding of the importance of higher education for people with disabilities, empirical research on this group remains quite limited (Peña, 2014), and most of the literature concerning students with disabilities has focused on learning disabilities (Heiman \& Precel, 2003; Kimball, Wells, Ostiguy, Manly, \& Lauterbach, 2016). Only a few articles have explored university students with visual impairment (VI), such as Lewin-Jones and Hodgson (2004), Myers and Bastian (2010), Pfau (2007) and Wong (2014). Many reviewed assistive technology (Bishop \& Rhind, 2011; Fichten, Asuncion, Barile, Ferraro, \& Wolforth, 2009; Gurb, 2000; Phatthanan, Singha, \& Chanboon, 2017; Wolffe, Candela, \& Johnson, 2003) or student support services and accommodations (Heiman et al., 2006; Hewett, Douglas, McLinden, \& Keil, 2017).

University students with VIs often face academic and social difficulties and thus develop their own means, methods, and skills to adjust to university life (Myers \& Bastian, 2010). Many discover that they do not have the learning skills necessary to meet academic demands. Some choose the so-called easy departments or must repeat some courses several times or lengthen the period of learning in university into an additional semester or even added years (Gurb, 2000). In Israel, the number of university students with VI remains low: only 400 students who identify/are defined as legally blind were enrolled in higher education institutions both years (Avgar, 2014; Hess, 2015). Empirical data on those students remain lacking in general, and data on students with VI are particularly scant, as only a few studies have detailed their higher education experiences. Most examined it through a special education or rehabilitative approach, in other words, acquisition of foreign language among students with VI (Krisi, 2014) or transition to higher education (Machmud, 2008). The current research uses a disability studies approach, a relatively new field in Israel (Ziv, Mor, \& Eichengreen, 2016) and thus focuses on various aspects of life in terms of disability, as socially un- derstood, rather than in terms of living with a VI per sein terms of medicalized discourse (Thomas, 1999). As of 2018 , still no academic program for disability studies in Israel exists, which might be one of the reasons for the anachronistic perception of the status of PWD in Israel and for university students with disabilities in particular (Almog, 2018).

I examined the academic journey of university students with VI, specifically the ways in which they experience their adjustment to university both academically and socially. The study explicitly seeks to incorporate student voices and, using in-depth interviews, to offer insight into students' experiences of their academic journeys. The aim is to raise awareness about how students with VI experience higher education, to improve the understanding of obstacles and barriers, and to shed light on the strengths and inner resources these students discovered along the way.

\subsection{The Emergence of Disability Identity}

Historically, disability was viewed as a purely medical phenomenon and as a tragedy for the individual marked as deviant and as an object of pity and patronage (Michalko, 2002). The "medical model of disability" placed responsibility for disabled persons' poverty and exclusion at their own doors, viewing this social predicament as an unavoidable outcome of the body or mind's functional impairments (Kanter, 2011). Critics of this model pointed to its systemic ignorance of social factors that mediate the experience of disability, which was then viewed purely as a phenomenon of the disabled body. This critique led to the establishment of the disabled minority as a political movement. The movement demanded recompense because of this group's discrimination and exclusion, which lie at the core of the appalling social suffering of people with disabilities (Barnes, Oliver, \& Barton, 2002). The new disability paradigm that has emerged in the 20th century describes disability as the product of the interaction between the individual and his or her environments. The model, also known as the social model of disability, "locates" disability in society and identifies social prejudices, inaccessible environments, discriminatory work arrangements, and segregated education as disabling societal elements (Oliver, 1996, pp. 32-33). The model stresses that specific problems experienced by people with disabilities result from the totality of disabling environments and cultures (Oliver, 2004). For example, visually impaired students are not disabled by their lack of sight but by the lack of accessible reading materials (i.e., Braille, audiobooks) and by stereotypical ideas about blindness.

Both the social model and the disability rights movement have empowered PWD by changing the way they think not only about themselves but also about society and the way they are included within. The body of knowledge that led to the emergence of the social model of disability is primarily concerned with both the "politi- 
cal project of emancipation" and the development of an "oppositional politics of identity" (Corker \& Shakespeare, 2002, p. 3). This perspective discusses disability identity as something fixed and stable, as the identity is "hypostasized and turned positive against the negative descriptions used by the oppressors" (Davis, 2006b, p. 231). Later scholars have critiqued the social model, as it has become a "generic term for social inclusion" (Shakespeare, 2018, p. 130), occluding the complexity of disabled people's day-to-day experiences. These scholars have redefined disability as a complex and multidimensional phenomenon composed of the individual, society, and biology and discuss disability identity as more fluid changes between both contexts and in relation to other identities of the individual (Watson, 2002). Disability identity refers to possessing favorable and positive views toward one's disability and feelings connected to others from the disability community. A coherent disability identity is believed to help individuals adapt to disability and instructs them how to act in different situations in which disability issues arise (Dunn, 2014).

Nario-Redmond, Noel and Fern (2013) examined disability identification and its effect on personal and collective self-esteem and noted the tension between an individual fluid disability identity to a distinct collective and empowered disability identity. Dorfman (2017) studied the way in which disability models translate into disability identities and how self-identity perceptions of Social Security benefits claimants clash with the one they need to perform in front of state officials in order to be considered eligible for benefits. A similar conflict between the identity as perceived by the self and the one needed to be projected and performed exists in regard to accommodations in higher education.

\subsection{Disability Identity Conflicts in Higher Education}

The higher education environment confronts students with disabilities and students with VI in particular in multiple situations in which such students stand out by being unusual, different, and uncommon and consequently activates disability identity conflicts (Dunn, 2014). Many of the practical difficulties that students with disabilities experience are due to environmental barriers and obstacles that directly result from an inaccessible educational environment (Almog, 2018; Titchkosky, 2009; Wisbey \& Kalivoda, 2016). This environment includes inaccessible learning materials, inequality in examination conditions, inadequate understanding of the students' needs, and lack of information about support services (Bishop \& Rhind, 2011; Wong, 2014). University students with disabilities are aware of this construction of disability within higher education and described it as "negative, stigmatized, and associated with something that is not normal" (Vaccaro, Kimball, Moore, Newman, \& Troiano, 2018, p. 46). Seale (2013) claimed that even the use of technology by students with disabilities is influenced by the academic pressure to be like other "normal" students.
The process of adjusting to campus life is a neutral phase in the individual's maturation process and represents the transition from dependence to interdependence/autonomy (McBroom, 1997). Because most students enter higher education while transferring from adolescence to young adulthood, they are also experiencing a "natural" maturation phase. Along with studying, the individual must leave the parents' home, find mutually satisfying relationships, and choose a profession. This is also the first time most students with disabilities must claim academic accommodation themselves, as during high school, this was the parents' responsibility. This requires self-advocacy and conflict resolution skills (Anctil, Ishikawa, \& Scott, 2008) but above all confronts students with their disability identity.

Attending university has implications for the way in which students with disabilities construct their personal and social identity (Borland \& James, 1999), as they are aware of the possible stigma associated with their impairment and seek to control others' perceptions to then be perceived as equals (Olney \& Brockelman, 2003). Social stigma can also lead to closeting and not identifying as a person with disability, affecting the use of institutional support services (Grimes, Scevak, Southgate, \& Buchanan, 2017) or making friends (Lourens \& Swartz, 2016). Passing as nondisabled through ingenious ways that conceal their impairments is one of the strategies for managing identity of people with disabilities (Siebers, 2004). Shakespeare (1996) also claimed that people with disabilities may use the denial strategy to minimize the impairment's effect on their lives by concealing their disabled identity and claiming to be "really normal".

According to Tajfel's (1978) social identity theory (SIT), people in a minority group not identified with the mainstream will be forced to confront a negative social identity, especially when their in-group is considered inferior. This negative perception might create a conflict between the individual's belonging to his or her in-group and belonging to the group representing the dominant culture. SIT and other psychological research have examined variations of disability identity and its occurrence in various contexts. Nonetheless, in contrast to other social identities (race, class, gender, etc.), disability identity is a relatively new category and has not been researched adequately in the context of higher education (Kimball et al., 2016).

The current article addresses this gap in knowledge and presents various disability identity narratives of university students with $\mathrm{VI}$ as experienced by them during their academic journey. It is also the first study in Israel to explore the topic of disability identity within higher education.

\section{Research Design and Methodology}

The study was longitudinal and qualitative in design and examined university students with VI's academic journey during 2 years of their studies. Each student was 
interviewed four times within this period. I collected and analyzed the data based on grounded theory principles (Glaser \& Strauss, 1967) and used an emancipatory research paradigm (Oliver, 1992), which draws explicitly on people with disabilities' collective experience and thus directly challenges this group's widespread social oppression. This paradigm affects the types of questions researchers ask and the way the answers to those questions are analyzed (O'Day \& Killen, 2002). Moreover, it encourages the generation and production of meaningful knowledge about various structures that create and sustain the multiple deprivations people with disabilities encounter (Barnes, 2003). Oliver (1992) detailed three essential principles in an emancipatory methodology that influenced the research design and process.

The three principles are as follows:

i. Reciprocity: the relationship between the interviewer and interviewees can never be completely equalized. In the current study, three things made that even more difficult to accomplish. First, most of the interviewees were undergraduate students, whereas I was a doctoral student. Second, the participants knew that my experience includes serving as a coordinator for students with special needs at the Open University, and they at times solicited my advice as a learning counselor. Third, the participants knew that I also face difficulties as a student with $\mathrm{VI}$ and frequently asked questions that were directed toward learning from my own experience of overcoming shared barriers. I did endeavor where possible to build on this relationship and make it as equalized as it could be. The sharing of experience was important, as some participants had felt isolated and unable to share their experiences with anyone else;

ii. Gain: the study participants possessed my contact details, and some used them to share their experiences with me-whether it was about issues that had arisen in the interviews or other topics outside of the research. Some interviewees mentioned that it was a therapeutic experience for them and that they looked forward to our subsequent meetings. It should be noted that none of the participants dropped out of university during the research period. This is not a representative characteristic of the population of university students with $\mathrm{VI}$ and must be considered when the results are analyzed. After the research was completed, the study's implications and recommendations were shared with professionals and support service administrators during several training sessions that the Israeli National Insurance Institute conducted. The institute had initiated a program to address the problem of access to higher education for students with disabilities by allocating substantial government funding to develop centers to support students with disabilities. Ultimately, through the dissemination of the research findings, I hope that greater inclusion and equality will be achieved for students with VI;

iii. Empowerment: the imbalance of power between people with disabilities and nondisabled people is well known. People with disabilities have been discriminated against throughout modern history in many aspects. The decision to carry out a research study and to make the experiences of a minority oppressed group known is, in itself, a form of self-empowerment (Vernon, 1997). The fact that several participants in the study provided the researcher with other contacts to interview, as occurred in this current study, "is also evidence of the same self-empowerment" (Vernon, 1997, p. 172). In addition, Vernon claimed that treating participants as equals helps them increase their self-confidence and self-esteem. Moreover, the sharing of experiences can literally prove empowering for the participants (Vernon, 1997).

Oliver (1992) suggested that empowerment is not something that can be given to people: people must undertake specific actions to bring about their empowerment. According to Oliver's view, researchers should ask whether their work is contributing to this empowerment process. The findings and implications of the current study were presented to those working with support services in higher education institutes and as a means of assisting the participants and the community of people with VI.

\subsection{Participants}

Participants included 16 university students and graduates, six men and 10 women, all defined as legally blind. Eight of the students were completely blind (five from birth), and the other seven were visually impaired. Ten participants were studying for their BA and five for master's degrees, and one had graduated with his bachelor's degree. Students ranged in age from 20 to 35 . Although some of the students have a visible disability and could be identified immediately upon entering a room (via use of a cane or guide dog or an unusual eye appearance), others have a hidden disability, allowing them to pass as nondisabled.

All participants were identified by pseudonyms. Other identifying details (university's name, department of study, etc.) were also changed to ensure anonymity.

\subsection{Method}

I collected data through in-depth, semi-structured interviews. This allowed participants to express the meanings they ascribe to the behavior, feelings, thoughts, and perceptions they and others hold in their own language and with their own concepts. During the interviews, participants were asked to describe their lives "from the per- 
spective of being a university student with VI". All interviews were audio-recorded.

The interview structure was flexible and dynamic. I sought to allow the participants to share their stories in their own way. I tried not to interfere or give clear directions (e.g., where the story begins, what is important, and what is not) to allow participants to bring forth their personal narratives of being a student with VI. After the participants finished telling their stories, I reviewed the interview guide. If the following topics were not mentioned, participants were asked about them. These included the following: high school experience; military or national service (if it existed); choice of university and department; learning experiences; contact with tutors and lecturers; use of assistive technologies; contact with readers; orientation and mobility issues; accommodations, friendships, and social interactions; and perceptions of failure and success.

After three periods of interviews, a list of categories and themes had emerged from the data up until that point. The fourth interview was the only one conducted differently. It included a list of 10 questions regarding the themes that had emerged from the previous interview and that had been analyzed. The questions concerned a meta-cognitive analysis and introspection on the different periods of studying in university, screening of the support the students used, learning skills that were acquired, and so on. This interview purpose was to validate the findings with participants. After the fourth period of interviews had ended, I understood that the research had reached it saturation point-that point occurs when "gathering fresh data no longer sparks new theoretical insights, nor reveals new properties of your core theoretical categories" (Charmaz, 2006, p. 113). The Ethics Committee of Bar Ilan University, Israel, granted study approval.

\subsection{Procedure}

I recruited students via snowball methods and through Internet forums and support services. Students were contacted by telephone and email and then provided general study information. I conducted all interviews. Most were carried out on campus and some in students' houses or in the dormitories. The interviews took from 90 minutes to three hours. I took steps to create a comfortable and accepting atmosphere in all the interviews. With the interviewees' written consent, interviews were audio-recorded and transcribed. Data constituted more than 650 single-spaced pages of text composed of transcripts and analytic memos. I analyzed the interview data according to themes (content analysis). Content analysis of the data created a grounded theory, which provides an overview of the academic journey of students with VI and meaningfully explains this journey's characteristics. The theory is constructed through a systematic process of repeatedly returning to the field to collect reams of data until a meaningful, rich theory has been constructed (Shkedi, 2003).

\section{Research Findings \& Discussion}

When I called Tal, one study participant, to schedule a meeting, she asked: "Why are you researching students with VI? We are just like any other students". After a short conversation, I convinced her to meet me to discuss the meaning of being a student with VI. I stressed that the research intent was not to look for the differences between sighted students and students with VI but to incorporate students' voices, which might also demonstrate similarities between these two populations. The question Tal asked is one that students with VI confront every day. It is a question of identity. At that point, I assumed that Tal's statement reflects the fact that, for her, having a disability is merely one aspect of her identity and not the sum total of it. Like Tal, all the participants in the current study discussed similarities and differences between them and nondisabled students.

Seven distinct themes emerged from the data. The first, which is also the core category, presents two complementary narratives participants used while configuring their identities. The second relates to environmental barriers in the academic world. The third describes the tension between independence and dependence. The fourth relates to impairment effects (Thomas, 1999) and their interactions and effects on the experience of the research participants. The fifth presents different ways to create social interactions and their importance for students with VI. The sixth describe the process of selfdisclosure, and the last theme describes internal and external forces that helped students with VI throughout their academic journeys. This article focuses on the "core category" of the theory that emerged from the interviews' data. The core category is the central phenomenon, through which all other categories can be organized and that occurs both as the phenomena's reason and as their result (Charmaz, 2006).

This category presented the question of constructing an identity of students with VI. Two answers to the question "Who am I?" were presented. Whereas the first answer is "I'm just like the others", the second one is "The others are just like me". These two answers are different sides of the same coin.

During the interviews, students mentioned in various ways that they are just like everyone else and that the others are just like them. Everyone has some kind of disability and has some level of dependence on others, visually impaired or not. This approach universalizes disability (Zola, 2005) and erases the boundaries between people with and without disabilities.

Students were aware of the perceptions society holds toward disabled people and try to fight them. Davis (2006a) claimed that every aspect of our life includes some idea of a norm, mean, or average that can be calculated (school tests, weight, salary, intelligence, etc.), and that people have an "inherent desire to compare themselves to others" (Davis, 2006a, p. 3). The study's participants adopted this view about normalcy and were 
busy locating themselves, but others too, on a continuum between disability and normalcy. The participants discussed two differing narratives that located them on this continuum. The first more common one emphasizes that they can do everything, just as sighted students can. The second makes sighted society into a disabled society one way or another. It seems that by using these complementary narratives, participants normalize their disability or disable normalcy. This situation is similar to the third stage of Gill's (1997) positive disability identity formation process. This stage, termed "coming together", concerns people with disabilities' understanding of being both part of nondisabled society and part of the disability community.

Using the two narratives, normalizing disability and disabling normalcy, is one way whereby people with disabilities might try to pass as nondisabled, though not in its classic sense of concealing disability but through decreasing the gaps between them and able-bodied others. Siebers (2004, p. 5) defined the "dominant social position simultaneously as normative and desirable". Through passing, people can improve their social status and increase chances for social acceptance. These two narratives will be presented in the following sections.

\subsection{Normalizing the Disability: I Can Do It Just Like Everyone Else}

Some of the students described their efforts to do things the way sighted students do. Adva for example told me about difficulties she had had in a certain course in her first year due to her impairment. When I asked her why she had not sought accommodations, she answered: "It doesn't look good to complain when you're a freshman". This means that Adva completely ignored the fact that the difficulty she had experienced resulted directly from her inability to see the learning material. Instead, she preferred to act as a sighted student, and for a first-year sighted student, complaining is a liability. In another situation, someone offered to call her a taxi, but she insisted on using the bus "just like everyone else". Racheli, an MA student who had lost her sight at 13, also stressed this idea by saying: "People do not know that we [blind people] are capable of doing everything; I say everything, and I mean it".

The influence of the social mechanism, which leads us to fit the criterion of being normal, is extremely common today in many facets of everyday life. Many wish to standardize our whole being toward what GarlandThomson (1997, p. 8) has called the "normate", which represents the collective's culture with its normative characteristics. Though Garland-Thomson (2002) primarily described processes of normalizing the body (reconstructive procedures, plastic surgery, etc.) and suggested that these procedures' goal is to improve the patient's psychological well-being, I propose that normalizing other aspects of the disability identity is done to achieve the same goal. These findings align with
Watson's (2002) findings, suggesting that for some individuals, both impairment and difference are not perceived as important to the sense of identity, and people with disabilities do not perceive themselves as different from the nondisabled. Dorfman (2017) defined this sub identity category as "quasi-normalization" because people who use it do not define themselves by their disability and reject its implications for their lives. As presented here:

I'm a blind student, but let's say it's not primary but secondary, I will not present my blindness before anything else, only "by the way". I live with roommates at the dorms-you know, my life is ordinary. Sometimes the blindness makes it difficult, but it's not the central thing in life. That's it. (Dana)

Many times I try not to mention my impairment or whine about it. I always try to submit papers on time and not to postpone things, but it doesn't work all the time, because I depend on others. (Orly)

Certain students use this approach, and its main idea is driven by the "people first" language, which stresses that persons come before the disabilities/impairments and that disability is something that accompanies people. As Nadav explained:

There is the person and then the disability....I'm a person with blindness, and I must put myself up front with my abilities but also let people be angry at me...when you are a person with a disability, people just pity you...suddenly you are just a nice guy, and one of the things is not to be just a nice guy, to have your opinions, what you think, not to take on that attitude that I'm handicapped, but to be me, a person with a disability who feels and thinks.

It seems that this narrative of normalizing the disability occurs in different ways of thinking and in various levels of analysis in the participants' discourse. Eitan, an MA student with VI, tried to explain the rationale behind this way of thinking through his discussion of his childhood experience of being disabled:

My tryout to be a normal kid and trying to integrate works in a logical/non-logical way, saying that if I hide it [the impairment], I will be like everyone else; if I'm like everyone else, I can fit in. You have this feeling of some kind of defect that you have and that you just want to hide it....[My] parents always allowed me to do everything. At bicycle age, I had one, everythingso what if I fall; so what? They always said, "So what?" Judo. So I did judo; so I always wanted to integrate, to fit in, and this is the way to do so.

Eitan, as many other persons with disabilities, was socialized into the understanding that a disability marks you as 
an outsider who cannot fit into the mainstream or integrate. The desire to be like everyone else, to normalize the disability, is very clear from the perspective of this socialization process. Throughout their lives, people with disabilities are "constantly bombarded with the values of the dominant culture" (Charlton, 2006, p. 222) and are required to be "like everybody else".

\subsection{Disabling Normalcy: Everyone Has a Disability}

The other way to understand the ambivalence of being a university student with $\mathrm{VI}$ is via making the sighted society into a disabled society. As Adva described it: "Everyone is normal, and everyone has a disability"; or in Rachely's words: "Everyone has his or her own package".

Some of the students described difficulties they face while studying. They know that every student faces difficulties when studying. Rebecca described her experience of getting to know people and places during the first semester of the first year as difficult due to her VI but then regretted this and said: "I couldn't understand that all the students here felt exactly the same as I did".

Trying to face the challenge of being disabled, some of the students claimed that, in some way, everyone is disabled, everyone faces difficulties stemming from studying at university, and other students may be occasionally dependent on others in some manner. By framing things this way, students transform being disabled or dependent into something ordinary.

Now I'm helping others, and I say, "Hey, what's wrong here?" I thought I'm the one who needs help...but suddenly I saw that this student is just staring, and the other asks for summaries from the others, so I found out that it's a part of being a student, whether you are impaired or not. (Ayelet)

No one understands anything during the first semester, and everyone thinks that the others do understand; it's really frustrating. During the first year, you just learn how to manage, and it has nothing to do with you. (Eitan)

Statistics is so difficult...and who the lecturer is is so important; people suffer from it [this situation] whether visually impaired or not. (Rebecca)

It seems that sometimes by thinking of others as facing the same difficulties, students thus "normalize" their experience and present it as part of human diversity. This way of thinking is another way to reduce the gap between students with and without disabilities, and it can serve to bolster students' positive self-perception.

A critical look at this narrative exposes that the boundaries between disability and able-bodiedness are extremely fragile. In fact, as McRuer (2002, pp. 95-96) puts it:
Everyone is virtually disabled, both in the sense that able-bodied norms are 'intrinsically impossible to embody' fully and in the sense that able-bodied status is always temporary, disability being the one identity category that all people will embody if they live long enough.

Moreover, some disability rights activists and disability studies scholars use the phrase "temporarily ablebodied" (TAB) as a reminder that many people will develop disabilities at some point in their lives due to accidents, illness, or aging.

Dvir referred to this concept when discussing his frustration about accessibility on campus:

Why is it so difficult to install an accessible name plate (bold/large print/Braille), one that you can grab onto? It costs nothing....This opacity is so frustrating for me because you can go blind at any given moment. You can walk the street in Ashkelon and suddenly a missile falls and you are blind. But people do not understand this.

I do not claim that the participants were aware of this critical thinking, but it seems that they do hold a deep understanding of the fragility of life and that disability and ablebodiedness are concepts on a continuum rather than being dichotomous concepts. This understanding makes it easier for the participants to minimize the differences between them and members of nondisabled society who, through this lens, become formed as TAB.

\subsection{Compulsory Able-Bodiedness and Disability Identity Conflicts}

By using the two narratives presented above, study participants were simultaneously negotiating identities both as students and as persons with VI. McRuer (2002), inspired by Adrienne Rich's concept of "compulsory heterosexuality", coined the term "compulsory ablebodiedness" as an ethos that presents the able body as an ideological norm: a sign of beauty, strength, health, and power. As able-bodiedness is constructed as a norm, disability is an exception constructed to preserve it in the binary system in which the norm is defined and constructed as its opposite. Kafer (2003) claimed that one of the ways in which compulsory able-bodiedness works is through what Rich calls, "control of consciousness"assume able-bodiedness unless otherwise stated. This last mechanism pushes people with invisible disabilities to pass as nondisabled and confronts them with the dilemma of identifying or avoiding their disability identity. For people with apparent disability, compulsory able-bodiedness brings forth the concept of cure and healing-because disability, satisfaction, and quality of life cannot all coexist. The system of compulsory able-bodiedness demands that people with disabilities respond affirmatively to the "unspoken ques- 
tion": "Wouldn't you rather be able-bodied?" (Kafer, 2003). This social mechanism justifies the desire of participants in the current study to identify as normal and able-bodied.

Disability is much more than the clinical medical definition of one's impairment. Compulsory able-bodiedness is a tool the mainstream culture uses to silence, erase, and exclude the disabled existence. It seems that the higher education environment constantly drowns us with a message that demands that students meet the normalcy criteria in order to "fit in".

Orly, a congenitally blind MA student, shared an event wherein the demand to be "like others" was used against her. Orly wanted to submit an application to split her first-year courses over two years:

The head of my department just does not care whether I have enough readers or not. In her opinion, "You are like everybody else". It has already been said before: "You are like everybody else, a student like every other student, so try to be like everyone else". Well great! I try to be like everyone else, but for the record, I am not like everybody else.

This quote exemplifies how the "normalize the disability" narrative collapses due to the disabling environment. Even though the head of the department holds the same idea as the study participants do and tries to normalize Orly, Orly claims that she is not like the others. By presenting this disability identity, Orly indicates that academic accommodations are the base essential of creating inclusive higher education.

Dvir, a BA student with VI, described a similar event with one of the lecturers:

I asked them to print the assignments in Infi [Infinitesimal calculus] instead of writing it because I cannot see. I went and talked with the teaching assistant, and he told me that there is nothing that could be done about it. I spoke with the lecturer, and what did she say to me? "There is nothing to be done; you should be able get along with it like everyone else! If you cannot see it, you do not know math.

Dvir's lecturer uses an abelistic approach in which you are not able to know math if you cannot see, a demand that reflects a naturalized perception of the able body. Being visually impaired is subordinated in an environment that values normalcy. Both Orly and Dvir must identify as disabled to obtain the accommodation that will allow them equal participation in higher education, but when they do so, they are confronted with derision and with significant feelings of inferiority. These sorts of reactions to students with disabilities are just a part of the attitudinal barriers these students face every day and significantly affect the students' experiences.

These events demonstrate the powerful meaning of normalcy that students with disabilities meet and just might stand at the base of the "normalize disability" narrative. It seems that by using this narrative, students demand others to see them as equal and as suitable for higher education. Jonathan, a first-year student, also explained how important it was for him to build his timetable all himself. He said:

I made such an effort that I even fell down the stairs. I walked through places I don't know; no one helped me or accompanied me. I made it on my own. This is one of the most important things for a student.

It seems that Jonathan avoided the support he needed so he could gain a sense of independence and ability that makes him feel as though he is like all the other students. Study participants used this tool similarly, trying to integrate, fit in, and be accepted in the university environment. Only after the students can perceive themselves as having integrated, in their self-perception, can they demand their rights.

The use of compulsory able-bodiedness also explains why the "normalizing the disability" narrative was used more frequently than the "disabling normalcy" narrative was. The able-bodied institution allows the continued oppression of people with disabilities. Through the construction of normalcy, people with disabilities are excluded in multiple ways. Thus, the strategies that participants in the study used to gain access to the university environment are the means of declaring themselves disabled but normal, exactly like the other students, or alternatively, of claiming that others are also disabled, only in different ways.

\section{Conclusions and Implications}

The most significant issue participants dealt with during their academic journeys was their identity and its location on the continuum between disability and normalcy. However, this location changed throughout each of the research interviews and over time. When I asked participants to tell their stories of being a student with $\mathrm{VI}$, students primarily discussed the similarities and the differences between them and sighted students, as presented in this article. The two complementary narratives, "normalizing disability" and "disabling normalcy", that the participants used stem from the struggle students with $\mathrm{VI}$ faced during their lives, while trying to fit in and be included in the mainstream, into nondisabled society. These struggles are even more powerful in the higher education institutional environment, in which able-bodiedness and normalcy are central requirements for participation, both socially and academically. The interchangeable use of these narratives regarding students' disability identity aligns with Siebers' (2008, p. 4) definition of disability identity as an "elastic social category".

One of the study's aims entails raising awareness of how students with VI experience higher education and improving the understanding of barriers and enablers 
these students discover along their academic journey. Faculty, staff, and university support services can make a profound difference for a student with VI. Whether through administrative assistance (i.e., helping students navigate the campus itself) or through academic accommodations (i.e., provide assignments in different accessible formats), support services are crucial. To facilitate such support, universities must promote an understanding of disability identity conflicts within higher education-among staff, faculty, and students with disabilities themselves. It also must be recognized how the compulsory able-bodiedness mechanism works within higher education and be acknowledged that making this environment inclusive demands a widespread culturalorganizational overhaul. This can be undertaken via training sessions for staff and faculty, which Israeli law requires of every higher education institution, and via joint working groups composed of people with and without disabilities seeking to promote an institutional inclusive environment. Israel's new regulations regarding accessibility of higher education institutions will take full effect in the near future (in November 2018), making this an opportune time to consider how dilemmas concerning disability identity can shape how we establish support services and provide them to students with disabilities. Although further empirical evidence would demonstrate the importance of these students' developing a positive disability identity, another question to be asked is how higher education can encourage the development of such. As issues of disability identity are part of the field of disability studies, it is important to develop an academic infrastructure/foundation for disability studies in Israel and throughout the world. The absence of such an infrastructure might be one reason that disability issues remain under-theorized. As Titchkosky (2009, p. 38) claimed, there is an intimate relationship between establishing disability studies "as a form of critical knowledge production within the university and creating accessible learning environments" where students with disabilities, but also faculty, staff, and support services, can succeed.

\section{Acknowledgments}

The research was supported by the Presidential Scholarship for Excellence, Bar-Ilan University. I thank all the students who have shared their stories with me throughout the years. I also gratefully acknowledge the anonymous referees whose careful responses to this article have dramatically improved it.

\section{Conflict of Interests}

The author declares no conflict of interests.

\section{References}

Almog, N. (2018). "Something here stops me". University students with disabilities in Israel: Policy, discourse and practice. Keshet-Journal of Social Science \& Humanities, 1, 31-65.

Anctil, T. M., Ishikawa, M. E., \& Scott, A. T. (2008). Academic identity development through selfdetermination: Successful college students with learning disabilities. Career Development for Exceptional Individuals, 31(3), 164-174.

Avgar, I. (2014). Education services for people with visual impairment and blindness. Jerusalem: The Knesset Research Institute. Retrieved from fs.knesset.gov.il/ globaldocs/MMM/4f5c6b58-e9f7-e411-80c8-00155 d010977/2_4f5c6b58-e9f7-e411-80c8-00155d0109 77_11_7816.pdf

Barlev, L., Admon-Rick, G., Keren-Abraham, Y., \& Haber, Y. (2017). People with disabilities in Israel, 2017. Jerusalem: Commission for Equal Rights of Persons with Disabilities and the Myers-JDC-Brookdale Institute. Retrieved from brookdale.jdc.org.il/ publication/people-with-disabilities-2017

Barnes, C. (2003). What a difference a decade makes: Reflections on doing "emancipatory" disability research. Disability \& Society, 18(1), 3-17.

Barnes, C., Oliver, M., \& Barton, L. (2002). Disability studies today. Cambridge, MA: Polity Press.

Berman, A., \& Naon, D. (2004). University graduates with visual impairment and blindness: The contribution of ALEH Foundation during their studies and follow-up on their transition to employment. Jerusalem: JointBrookdale Institute.

Bishop, D., \& Rhind, D. J. A. (2011). Barriers and enablers for visually impaired students at a UK Higher Education Institution. British Journal of Visual Impairment, 27(3), 177-195.

Borland, J., \& James, S. (1999). The learning experience of students with disabilities in higher education: A case study of a UK university. Disability \& Society, 14(1), 85-101.

Bruder, M. B., \& Mogro-Wilson, C. (2010). Student and faculty awareness and attitudes about students with disabilities. Review of Disability Studies: An International Journal, 6(2), 3-13.

Charlton, J. I. (2006). The dimensions of disability oppression: An overview. In L. Davis (Ed.), The disability studies reader (pp. 217-227). New York, NY: Routledge.

Charmaz, K. (2006). Constructing grounded theory: $A$ practical guide through qualitative analysis. Thousand Oaks, CA: Sage Publications.

Corker, M., \& Shakespeare, T. (2002). Mapping the terrain. In M. Corker \& T. Shakespeare (Eds.), Disability/postmodernity: Embodying disability theory (pp. 1-17). New York, NY: Continuum.

Davis, L. (2006a). Constructing normalcy: The bell curve, the novel, and the invention of the disabled body in the nineteenth century. In Davis, L. (Ed.). The disability studies reader (pp. 3-16). New York, NY: Routledge.

Davis, L. (2006b). The end of identity politics and the beginning of dismodernism: On disability as an unsta- 
ble category. In L. Davis (Ed.), The disability studies reader (pp. 231-242). New York, NY: Routledge.

Dorfman, D. (2017). Re-claiming disability: Identity, procedural justice, and the disability determination process. Law \& Social Inquiry, 42(1), 195-231.

Dunn, D. (2014). The social psychology of disability. Oxford: Oxford University Press.

Fichten, C. S., Asuncion, J. V., Barile, M., Ferraro, V., \& Wolforth, J. (2009). Accessibility of e-learning and computer and information technologies for students with visual impairments in postsecondary education. Journal of Visual Impairment \& Blindness, 103(9), 543-557.

Garland-Thomson, R. (1997). Extraordinary bodies: Figuring physical disability in American culture and literature. New York, NY: Columbia University Press.

Garland-Thomson, R. (2002). Integrating disability, transforming feminist theory. Feminist Formations, 14(3), $1-32$.

Gill, C. J. (1997). Four types of integration in disability identity development. Journal of Vocational Rehabilitation, 9(1), 39-46.

Glaser, B., \& Strauss, A. L. (1967). The discovery of grounded theory: Strategies for qualitative research. Chicago, IL: Aldine.

Grimes, S., Scevak, J., Southgate, E., \& Buchanan, R. (2017). Non-disclosing students with disabilities or learning challenges: Characteristics and size of a hidden population. The Australian Educational Researcher, 44(4), 425-441.

Gurb, E. (2000). Maximizing the potential of young adults with visual impairments: The metacognitive element. Journal of Visual Impairment and Blindness, 94(9), 574-583.

Heiman, T., Almog, N., \& Godder, E. (2006). Students with visual impairment and students with hearing impairment: Coping strategies and support services at the Open University. Topics in Special Education and Rehabilitation, 21, 33-44.

Heiman, T., \& Precel, K. (2003). Students with learning disabilities in higher education: Learning strategies and coping skills. Topics in Special Education and Rehabilitation, 18(1), 43-58.

Hess, I. (2015). Neither light nor :darkness Students with visual impairments and blindness in Israel. Tel Aviv: Mofet Press.

Hewett, R., Douglas, G., McLinden, M., \& Keil, S. (2017). Developing an inclusive learning environment for students with visual impairment in higher education: Progressive mutual accommodation and learner experiences in the United Kingdom. European Journal of Special Needs Education, 32(1), 89-109.

Israeli Ministry of Economy. (2013). Academics with disabilities: Data collection. Jerusalem: Ministry of Economy.

Kafer, A. (2003). Compulsory bodies: Reflections on heterosexuality and able-bodiedness. Journal of Women's History, 15(3), 77-89.
Kanter, A. S. (2011). The law: What's disability studies got to do with it or an introduction to disability legal studies. Columbia Human Rights Law Review, 42(2), 403-479.

Kanter, A. S. (2015). The development of disability rights under international law: From charity to human rights. New York, NY: Routledge.

Kimball, E., Wells, R., Ostiguy, B., Manly, C., \& Lauterbach, A. (2016). Students with disabilities in higher education: A review of the literature and agenda for future research. In M. Paulsen (Ed.), Higher education: Handbook of theory and research (pp. 91-156). Dordrecht: Springer.

Krisi, M. (2014). The journey to academic world: Contributing and impeding factors on learning among students with visual impairment and their effect on learning experiences in academia (Unpublished Dissertation). Bar Ilan University, Israel.

Lewin-Jones, J., \& Hodgson, J. (2004). Differentiation strategies relating to the inclusion of a student with a severe visual impairment in higher education (modern foreign languages). British Journal of Visual Impairment, 22(1), 32-36.

Lourens, H., \& Swartz, L. (2016). "It's better if someone can see me for who I am": Stories of (In)visibility for students with visual impairment within South African Universities. Disability \& Society, 31(2), 210-222.

Machmud, H. (2008). Being a university student with visual impairment: Experience and meaning (Unpublished Master's Thesis). Haifa University, Israel.

McBroom, L. W. (1997). Making the grade: College students with visual impairments. Journal of Visual Impairment and Blindness, 91(3), 261-270.

McRuer, R. (2002). Compulsory able-bodiedness and queer/disabled existence. In S. L. Snyder, B. J. Brueggemann, \& R. Garland-Thomson (Eds.), Disability studies: Enabling the humanities (pp. 88-99). New York, NY: Modern Language.

Michalko, R. (2002). The difference that disability makes. Philadelphia, PA: Temple University Press.

Monikendam-Givon, Y. (2017). Making computer systems accessible to people: Vision disability at work. Jerusalem: The Knesset Research Institute. Retrieved from fs.knesset.gov.il/globaldocs/MMM/71cf722f-b 23f-e711-80d3-00155d0a0b20/2_71cf722f-b23f-e71 1-80d3-00155d0a0b20_11_8306.pdf

Myers, K. A., \& Bastian, J. J. (2010). Understanding communication preferences of college students with visual disabilities. Journal of College Student Development, 51(3), 265-278.

Naon, D., Strodberg, N., Ben-Shoham, A., Haran, D., Prior, R., \& Gealia, D. A. (2012). People with disabilities in Israel's working-age population: Prevalence, characteristics and employment status. Jerusalem: National Insurance Institute and the Myers-JDC-Brookdale Institute.

Nario-Redmond, M. R., Noel, J. G., \& Fern, E., (2013). Redefining disability, re-imagining the self: Disability 
identification predicts self-esteem and strategic responses to stigma. Self \& Identity, 12(5), 468-488.

O’Day, B., \& Killen, M. (2002). Research on the lives of persons with disabilities: The emerging importance of qualitative research methodologies. Journal of Disability Policy Studies, 13(1), 9-15.

Oliver, M. (1992). Changing the social relations of research production? Disability, Handicap \& Society, 7(2), 101-114.

Oliver, M. (1996). Understanding disability: From theory to practice. London: Macmillan Press.

Oliver, M. (2004). The social model in action: If I had a hammer. In C. Barnes \& G. Mercer (Eds.), Implementing the social model of disability: Theory and research (pp. 18-31). Leeds: The Disability Press.

Olney, M. F., \& Brockelman, K. F. (2003). Out of the disability closet: Strategic use of perception management by select university students with disabilities. Disability \& Society, 18(1), 35-50.

Peña, E. V. (2014). Marginalization of published scholarship on students with disabilities in higher education journals. Journal of College Student Development, 55(1), 30-40.

Pfau, H. (2007). To know me now. Qualitative Social Work, 6(4), 397-410.

Phatthanan, S., Singha, C., \& Chanboon, S. (2017). A conceptual framework for better understanding of factors influencing accessibility to a website and its acceptance by university students with visual impairments. IEEE Xplore. Advanced online publication. http://dx.doi.org/10.1109/ICITEED.2017.8250493

Pinto, O., \& Fass, H. (2014). Vocational rehabilitation for people with disabilities: Work integration, persistence and wage levels. Jerusalem: National Insurance institute, Research and planning administration.

Riddell, S., Tinklin, T., \& Wilson, A. (2005). Disabled students in higher education. London: Routledge.

Seale, J. (2013). When digital capital is not enough: Reconsidering the digital lives of disabled university students. Learning, Media \& Technology, 38(3), 256-269.

Shakespeare, T. (1996). Disability, identity and difference. In C. Barnes \& G. Mercer (Eds.), Exploring the divide (pp. 94-113). Leeds: The Disability Press.

Shakespeare, T. (2018). Still a health issue. Disability and Health Journal, 5, 129-131.

Shkedi, A. (2003). Words that try to know. Qualitative research: Theory and practice. Tel Aviv: Ramot Publication.

Siebers, T. (2004). Disability as masquerade. Literature and Medicine, 23(1), 1-22.

Siebers, T. (2008). Disability theory. Ann Arbor, MI: The University of Michigan Press.
Tajfel, H. (1978). Social categorization, social identity, and social comparison. In H. Tajfel (Ed.), Differentiation between social groups (pp. 61-67). London: Academic Press.

Thomas, C. (1999). Female forms: Experiencing and understanding disability. Philadelphia, PA: Open University Press.

Titchkosky, T. (2009). "To pee or not to pee?" Ordinary talk about extraordinary exclusions in a university environment. Canadian Journal of Sociology, 33(1), 37-60.

Vaccaro, A., Kimball, E. W., Moore, A., Newman, B. M., \& Troiano, P. F. (2018). Narrating the self: A grounded theory model of emerging purpose for college students with disabilities. Journal of College Student Development, 59(1), 37-54.

Vernon, A. (1997). Reflexivity: The dilemmas of researching from the inside. In C. Barnes \& G. Mercer (Eds.), Doing disability research (pp. 158-176). Leeds: The Disability Press.

Vickerman, P., \& Blundell, M. (2010). Hearing the voices of disabled students in higher education. Disability \& Society, 25(1), 21-32.

Vilchinsky, N., \& Findler, L. (2004). Attitudes toward Israel's Equal Rights for People with Disabilities law: A multiperspective approach. Rehabilitation Psychology, 49(4), 309-316.

Watson, N. (2002). Well, I know this is going to sound very strange to you, but I don't see myself as a disabled person: Identity and disability. Disability \& Society, 17, 509-527.

Wisbey, M. E., \& Kalivoda, K. S. (2016). College students with disabilities. In M. J. Cuyjet, .M F. HowardHamilton, D. L. Cooper, \& C. Linder (Eds.), Multiculturalism on campus: Theory, models, and practices for understanding diversity and creating inclusion ( $\mathrm{pp}$. 328-349). Sterling, VA: Stylus Publishing.

Wolffe, K. E., Candela, T., \& Johnson, G. (2003). Wired to work: A qualitative analysis of assistive technology training for people with visual impairments. Journal of Visual Impairment \& Blindness, 97(11), 677-694.

Wong, M. E. (2014). Support for students with visual impairments in higher education in Singapore: Considering university publicity materials conveying disability services and support. CAISE Review, 2, 62-76.

Ziv, N., Mor, S., \& Eichengreen, A. (2016). Disability studies in Hebrew: An emerging academic field. In S. Mor, N. Ziv, A. Kanter, A. Eichengreen \& N. Mizrachi (Eds.), Disability studies: A reader (pp.11-56). Jerusalem: Van Leer Institute Press.

Zola, I. E. (2005). Toward the necessary universalizing of a disabled policy. The Milbank Quarterly, 83(4), 1-27. 


\section{About the Author}

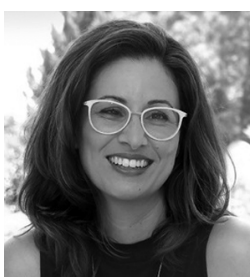

Nitsan Almog serves as the head of the Inclusive Education program at Ono Academic College and is a Lecturer at the Rehabilitation and Health MA program at the School of Social Work, Bar-Ilan University. She is also the lead consultant to the Israeli National Insurance Institute for the "Revolution in Higher Education", an entrepreneurial project that has established 35 support centers for students with disabilities in universities and colleges across Israel. She co-edited a special issue of Social Security (Israeli social policy journal) regarding the employment of persons with disabilities, in 2017. 